\title{
Behavioural Study of Shear Wall with Correlational to Bracing under Seismic Loading
}

\author{
Syed Muhammad Bilal Haider ${ }^{1}$, Zafarullah Nizamani ${ }^{1 *}$, and Chun Chieh Yip ${ }^{2}$ \\ ${ }^{1}$ Department of Environmental Engineering, Faculty of Engineering and Green Technology, \\ Universiti Tunku Abdul Rahman, Jalan Universiti, Bandar Barat, 31900 Kampar, Perak, Malaysia \\ ${ }^{2}$ Department of Civil Engineering, Lee Kong Chian Faculty of Engineering \& Science, Universiti \\ Tunku Abdul Rahman, Bandar Sungai Long, Cheras, 43000 Kajang, Selangor Darul Ehsan, Malaysia
}

\begin{abstract}
The reinforced concrete structures, not designed for seismic conditions, amid the past earthquakes have shown us the significance of assessment of the seismic limit state of the current structures. During seismic vibrations, every structure encountered seismic loads. Seismic vibrations in high rise building structure subjects horizontal and torsional deflections which consequently develop extensive reactions in the buildings. Subsequently, horizontal stiffness can produce firmness in the high rise structures and it resists all the horizontal and torsional movements of the building. Therefore, bracing and shear wall are the mainstream strategies for reinforcing the structures against their poor seismic behaviours. It is seen before that shear wall gives higher horizontal firmness to the structure when coupled with bracing however it will be another finding that in building model, which location is most suitable for shear wall and bracing to get better horizontal stability. In this study, a 15 story residential reinforced concrete building is assessed and analyzed using building code ACI 318-14 for bracing and shear wall placed at several different locations of the building model. The technique used for analysis is Equivalent Static Method by utilizing a design tool, finite element software named ETABS. The significant parameters examined are lateral displacement, base shear, story drift, and overturning moment.
\end{abstract}

\section{Introduction}

In the construction industry, high-rise building structures are currently the most sensitive, critical and difficult building models. They required more skills and efforts to prevailed over the horizontal seismic motions. To provide better stability to the building structures, different structure systems are utilized. Reinforce concrete bracing and Shear wall are the utmost prominent structural members which have a tendency to refrain from an early collapse [1].

Currently, in terms of better stability, stiffness and high performance, the Shear wall is a most common retrofitting technique used in low and high rise building models. Past search

\footnotetext{
* Corresponding author: zafarullah@utar.edu.my
} 
studies have confirmed that shear wall has the ability to absorb the ground motions and can oppose the impact of seismic activities.

Bracing and Shear walls are the most suitable and useful techniques for enhancing the ability to resist against seismic forces. These techniques can bear the seismic motions and act as a shield against earthquakes.

Bracing would transfer shear forces to the column. The pattern of transferring the forces through bracing is different. Bracing has many types of pattern, most common of them is X, $\mathrm{K}$, and inverted $\mathrm{V}$ [1]. Braced frames are a very common form of construction, being economic to construct and simple to analyze. Bracing provides stability and resists lateral loads. In braced construction, beams and columns are designed under vertical load only, assuming the bracing system carries all lateral loads[2]. Purpose of bracing is to dissipate the energy during the seismic ground motions. Bracing helps to minimize the displacement of a building structure. The material property of bracing (steel and concrete), location and shape of the bracing are the most important characteristic which can exert influence on behavioural properties of the member [1].

These days' engineers aim to make an outline for the protection of building from seismic and wind action. Shear wall deviate the horizontal forces and moves the forces towards the base of the structure. Shear wall protects from the sudden collapse of the building structure [2]. Shear walls are constructed to counter the effects of the lateral load acting on a structure. In residential construction, shear walls are straight external walls that work as a shield to protect the building model from seismic motions. If shear walls are designed and constructed properly, then they will have the strength and stiffness to resist the horizontal forces. Lateral forces caused by wind, earthquake, and uneven loads, in addition to the weight of structure and occupants; create powerful twisting (torsional) forces. These forces can literally tear (shear) a building apart. Reinforcing a frame by attaching or placing a rigid wall inside it maintains the shape of the frame and prevents rotation at the joints. Shear walls are especially important in high-rise buildings subjected to lateral wind and seismic forces.[2]

In this study, 15 storey residential building has been analyzed. Generally, both shear wall and bracings will provide an effective lateral stiffness. In this, the performance of the shear wall and bracings are to be compared for better results between them. For this, the equivalent static method of analysis has to be performed with the help of ETABS software.

\section{Literature review}

A 15 storey reinforced concrete residential building supported with both retrofitting technique bracing and the shear wall is analyzed according to Indian building code IS: 1893-2002 Earthquake resistant design of structures. All types of Bracing were considered in the study. Moreover, Shear wall has been allocated in different positions in the building. STAAD-PRO was used for dynamic analysis of the building. The result shows that Brace elements are very much efficient in reducing lateral displacement of frame as drift and horizontal deflection induced in braced frame are much less than that induced in shear-wall frame and plane frame. Though column axial force induced in braced frame is more than that in shear-wall frame and plane frame, however, the column and beam moments, and drift induced in braced frame are very less. Hence, braced frame is very efficient in resisting seismic force than shear-wall frame and plane frame [1].

A 5 Storey residential building is assessed in simulation software ETABS. The design code is IS 1893:2002. Performance of both bracing and shear wall was examined. The equivalent static method was selected in the study. Both the elements (shear wall and bracing) were analyzed separately in two similar model, one with bracing and other one 
with shear wall. It was concluded that there is a decrease in time period due to the placement of shear wall and bracing. Furthermore, the building model with the shear wall has the least storey drift as compared to braced building and bared frame [2].

A 10 storey building is analyzed in a finite element simulation software ETABS v15. Separate building models with the deferent position of the Shear wall having re-entrant corner have been examined. The non-linear dynamic method named time history analysis has selected in this study. Results show that dynamic response decreases the strength of corner walls as compare with side walls. The building will feel more stiffness and stability as shear wall location is close to the center mass of the building [3].

An 8 storey building model is examined in a finite element model ETABS. Building code IS 1983:2002 has selected. Two analysis method response spectrum and pushover analysis have been carried out. Bracings and shear walls are compared as seismic strengthening methods to buildings with plan irregularities. Results shows that similar performance provision of shear walls prove to be more economical and efficient method of strengthening the building with re-entrant corner compared to incorporation of bracings [4].

\section{Model and analysis}

In this study, 15 storey residential building is modeled and assessed by the software ETABS 2016. The shape of the building is regular and symmetrical. Structural building design code ACI 318-14 is considered. Dimensions of column and beam are $650 \mathrm{~mm} \mathrm{x}$ $500 \mathrm{~mm}$ and $550 \mathrm{~mm} \times 400 \mathrm{~mm}$. Members of each concrete element are formed of grade M30. Live and dead loads are distributed uniformly from slab on to beams. Seismic analysis method known as Equivalent static analysis is performed. Each floor in the building has the same height.

\subsection{General specification}

$\begin{array}{ll}\text { Number of bays in X direction: } & 5 \\ \text { Number of bays in Y direction: } & 5 \\ \text { Height of each storey: } & 4 \mathrm{~m} \\ \text { Grade of Concrete: } & \text { M30 } \\ \text { Slab Thickness: } & 200 \mathrm{~mm} \\ \text { Damping: } & 5 \% \\ \text { Grade of Steel: } & \text { A572 grade } 50 \\ \text { Importance factor: } & 1.5 \\ \text { Thickness of the Shear wall: } & 400 \mathrm{~mm}\end{array}$

\subsection{Shear wall and concrete bracing system}

Two separate building models for Shear wall and Cross typed reinforced concrete bracing are being modeled. Three model of shear wall and three model of concrete bracing have analyzed by changing the position of shear wall and bracing towards and away from the center of the residential building model. Buildings model are represented from figure 1 to 6 : 
In Figure 1, the location of the shear wall is at the centre of the building model in a square position. Shear wall is placed from base to the last floor of the building.
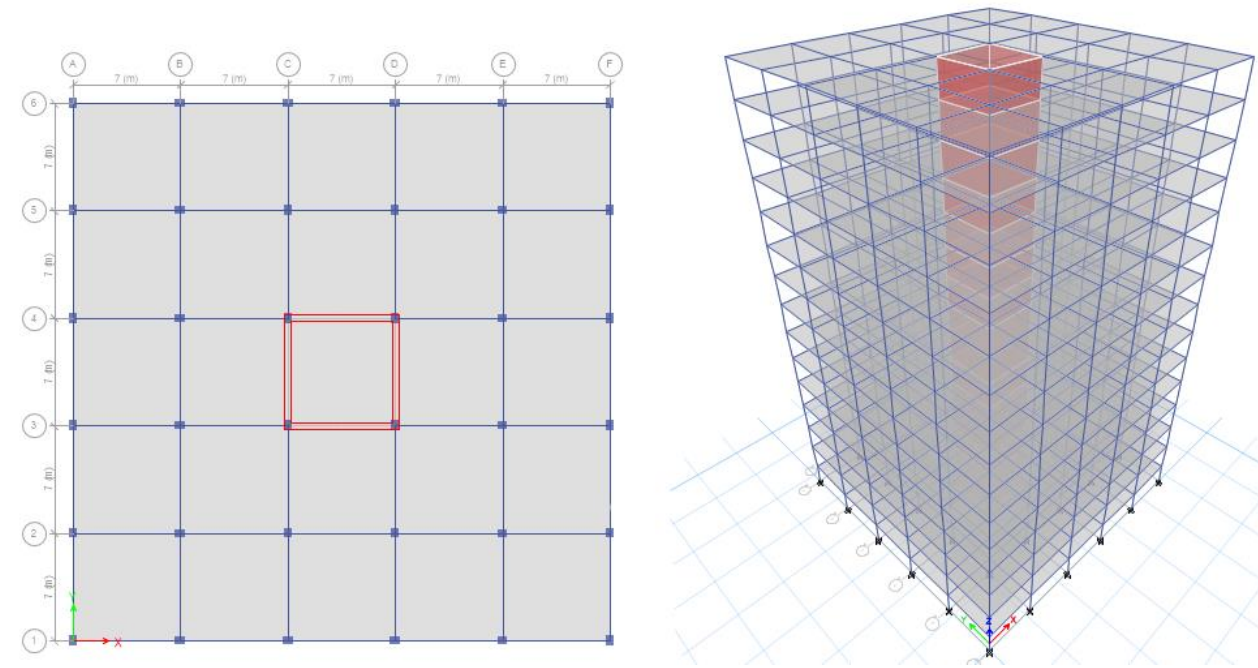

Fig. 1. Building with the Shear wall at the center

In Figure 2, Shear wall is moving away from the centre of the building model. Because of the position of the shear wall moving away from the centre and going towards the boundaries of the building model, such shear wall is termed as intermediate shear wall.

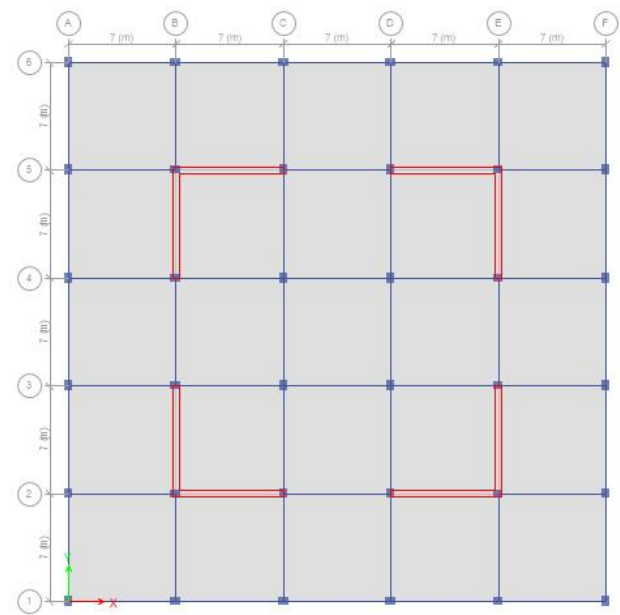

Fig. 2. Building with intermediate Shear wall

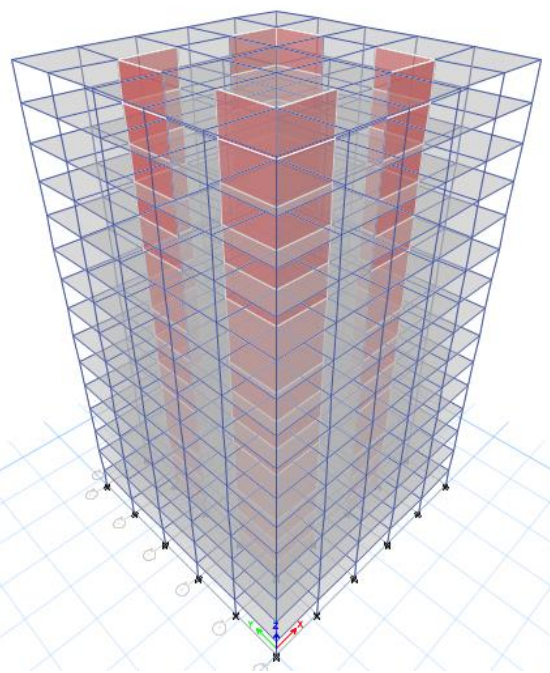


In Figure 3, Shear wall is presented at the four corners of the building model.
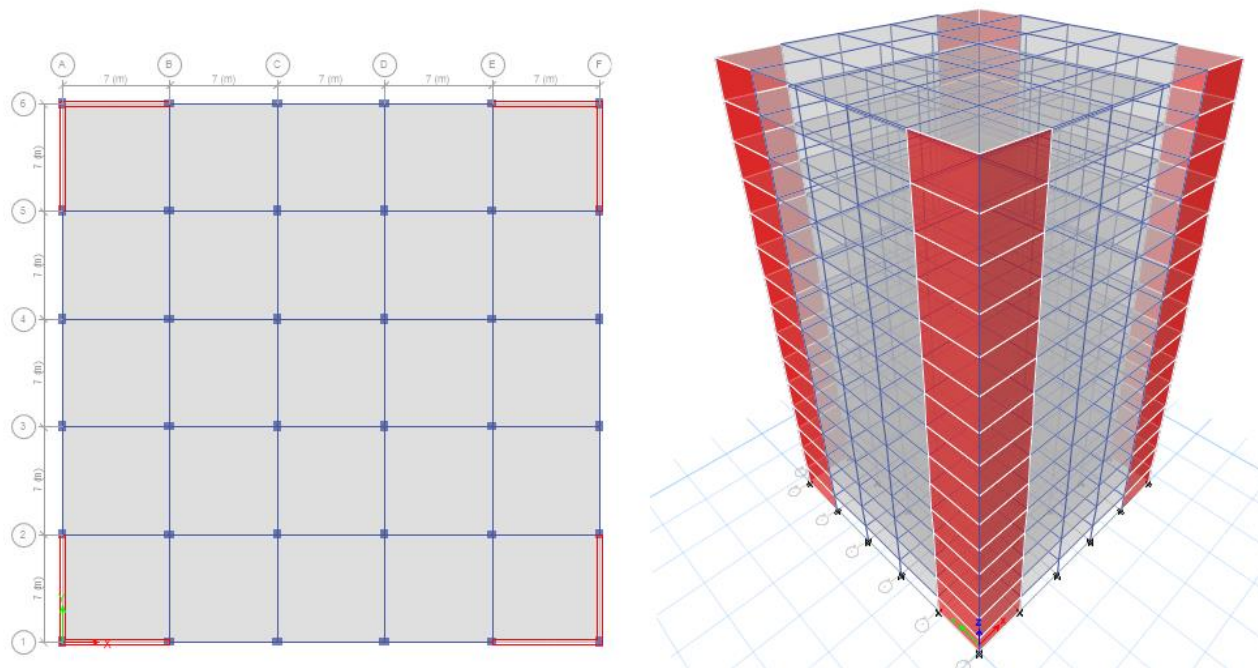

Fig. 3. Building with exterior Shear wall

In Figure 4, 5 and 6, Crossed bracing is provided at the centre, intermediate and exterior corners of the building model, whereas the same location where shear wall is placed in other separate building model.
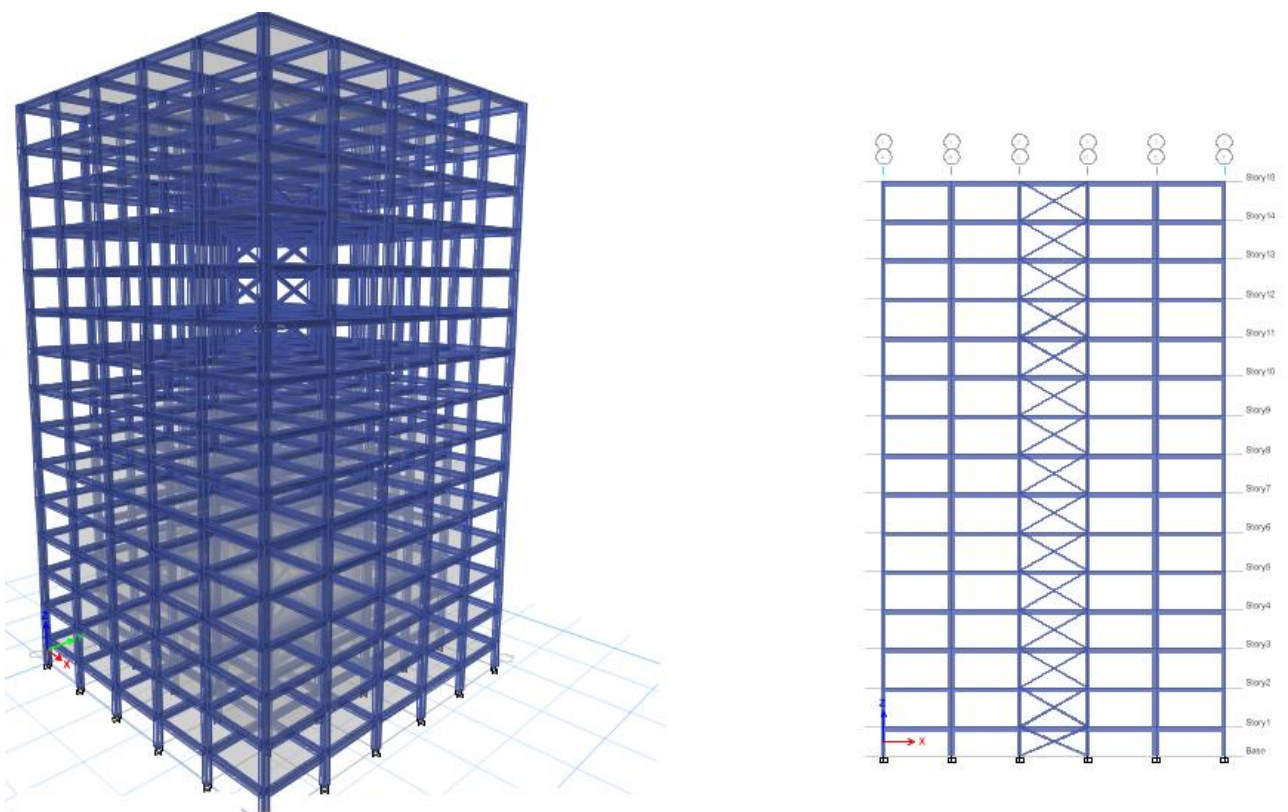

Fig. 4. Building with Cross Bracing at the center 

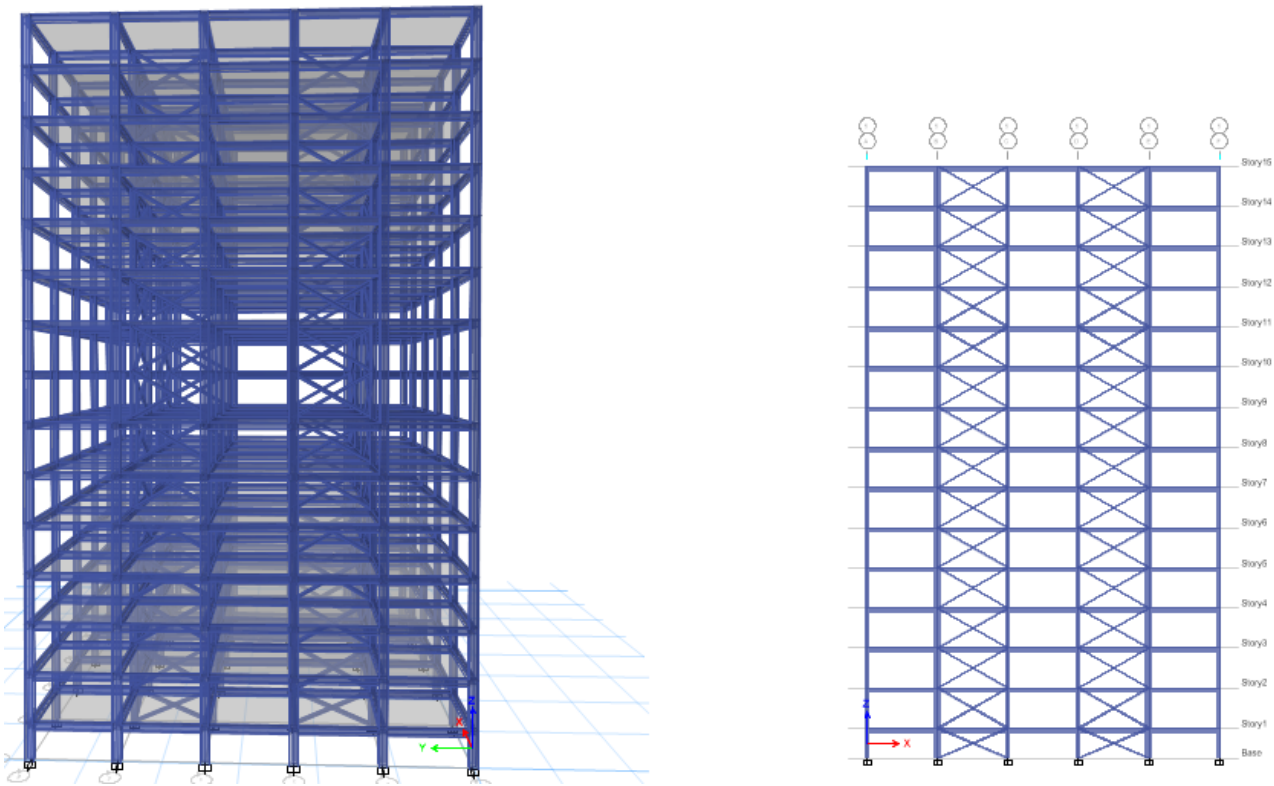

Fig. 5. Building with Intermediate Cross Bracing
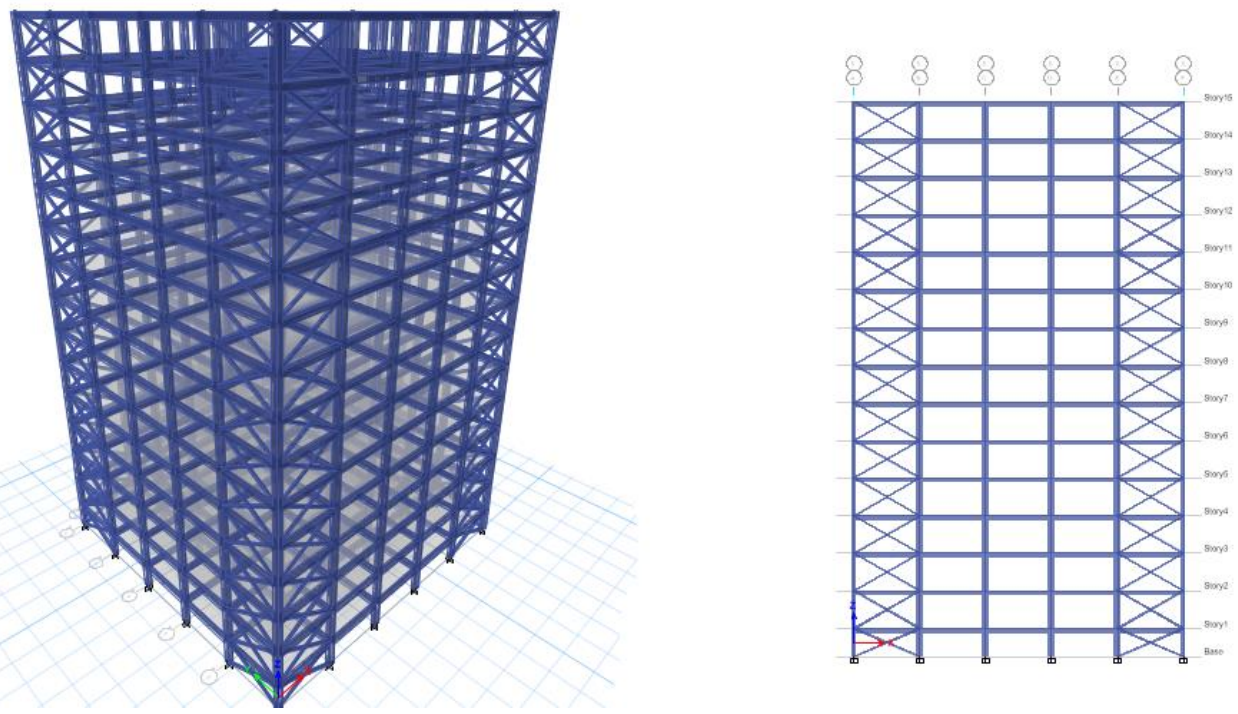

Fig. 6. Building with exterior Cross Bracing

\section{Results and discussion}

The results of Equivalent static analysis are shown in the figures 7 till 10. It is evident from the results of the analysis that both retrofitting technique, Bracing and Shear wall improve the performance of building model. 


\subsection{Storey displacement}

Figure 7 shows that the building model feel minimum storey displacement along the exterior corner bracing. It is prominent that performance of exterior shear wall is appreciable among the other shear wall positions. It is obvious that without the shear wall and bracing, building model will displace a maximum value. It is noted that as moving away from exterior corner to interior center of the simulated building model, there is an increase in the displacement for both bracing and shear wall respectively.

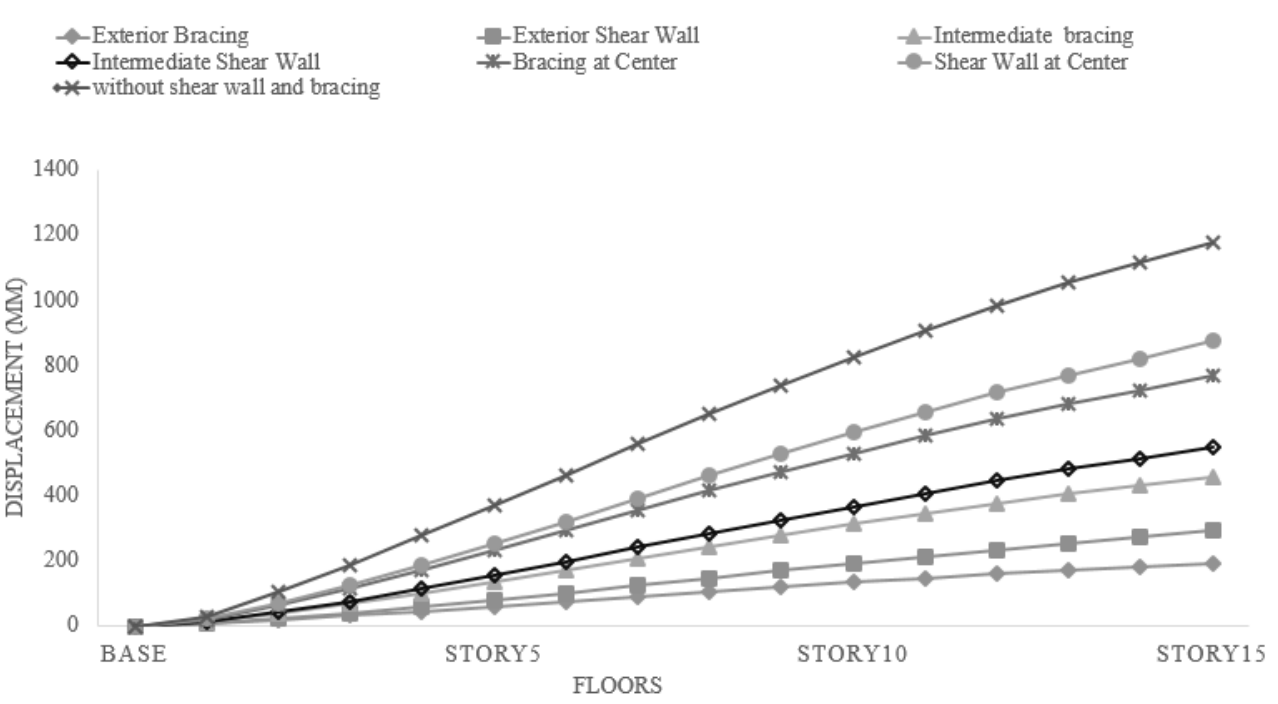

Fig. 7. Storey displacement in each building model

\subsection{Storey shear}

In figure 8 , storey shear in each floor is minimum in the intermediate shear wall of the model. When shear wall moving away from the centre and going towards the boundaries of the building model, such shear wall is termed as intermediate shear wall.

However, in term of maximum storey shear on each floor in each simulated model, the $12^{\text {th }}$ storey has the maximum value in each simulated building model. The graph clearly shows that the end value of each shear wall building model has an approximately similar value which represents that the position and movement in direction of the shear (towards or away from the center of the building) will not affect the end result. 


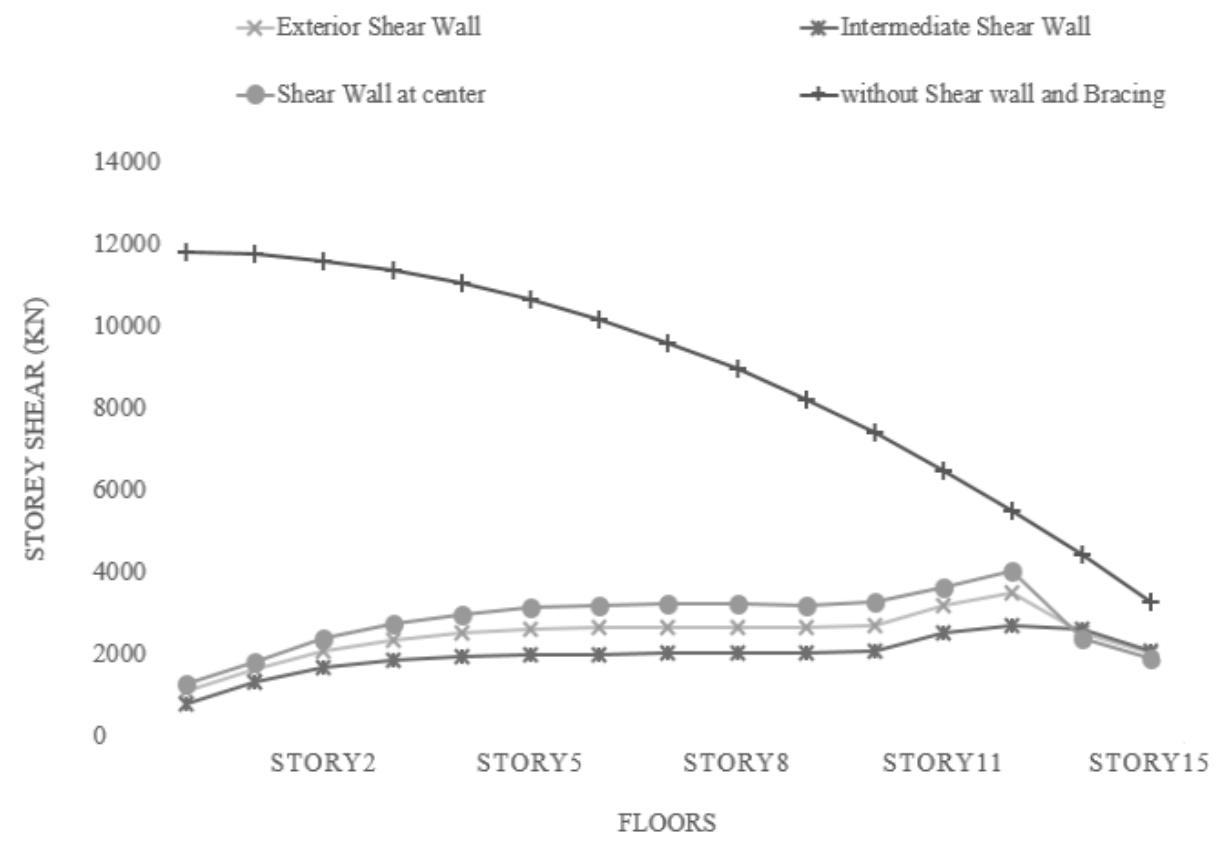

Fig. 8. Storey Shear in each building model along with Shear wall

Similarly, reinforced concrete bracing is not depending on the location and position in the building model. However, in terms of minimum storey shear, cross bracing has not selected the same location in figure 9 as the shear wall selected in figure 8. Exterior bracing is feeling the minimum storey shear however shear wall feels minimum storey shear at the centre.

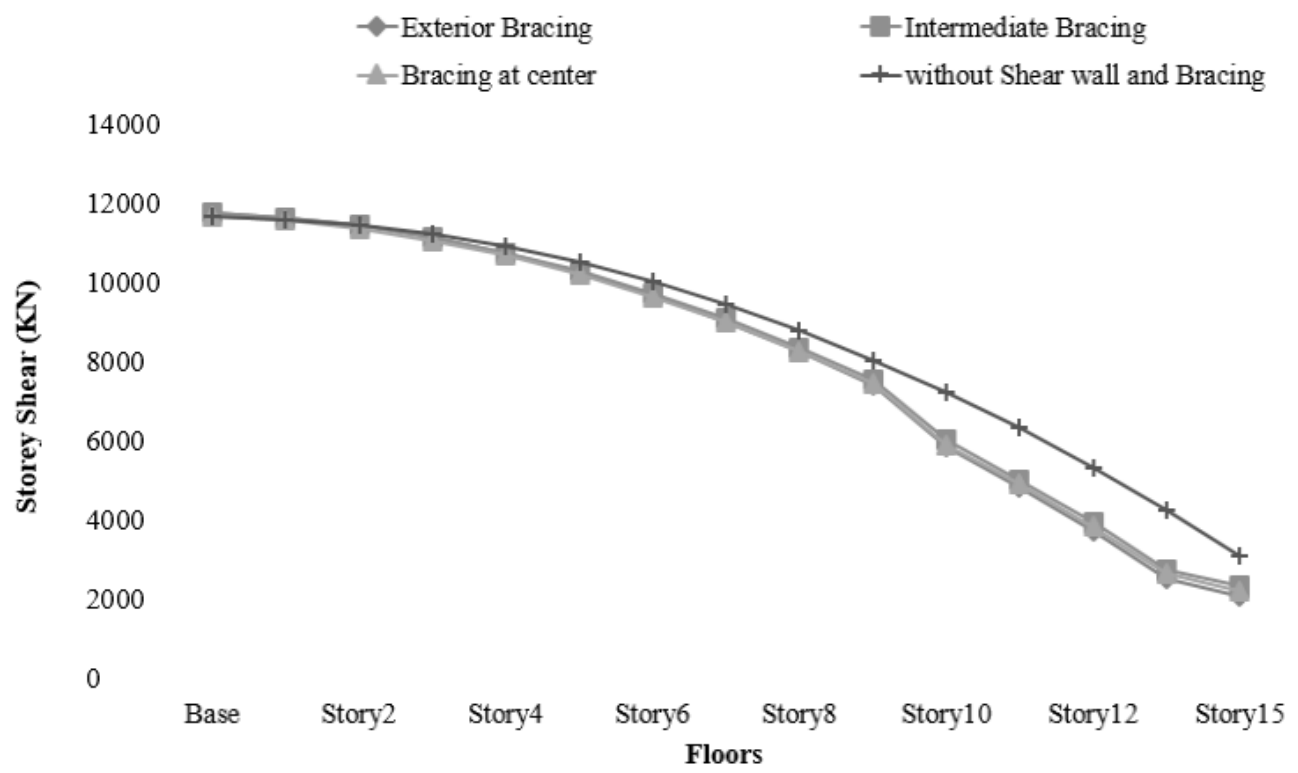

Fig. 9. Storey Shear in each building model along with bracing 


\subsection{Overturning moment}

The figure 10 shows that by changing the location of shear wall in the building, the overturning moment will vary. Figure 10 shows that Intermediate shear wall will be having least moment. However, bracing does not depend on the location and position with in the building model.
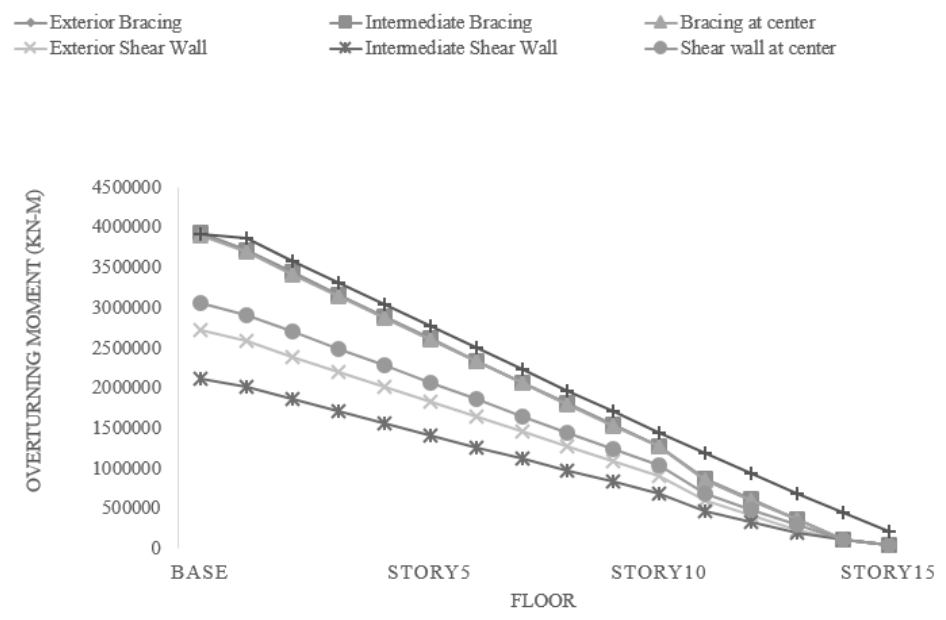

Fig. 10. Overturning moment in each building model

\section{Conclusion}

In this study, both bracing and shear wall have introduced to examine the effects on building model in seismic conditions. It is clear that building model with shear wall and bracing will show more stability and stiffness in correlation without retrofitting members. It has been found that as moving away from the center of the building, the storey displacement will get decreased. Furthermore, bracing at exterior corner will be most effective in facing the lateral drifts.

The authors acknowledge the financial support through UTAR-RF grant no. IPSR/RMC/UTARRF/2016-C1/Z1 provided by Universiti Tunku Abdul Rahman (UTAR).

\section{References}

1. S. R. Thorat and P. J. Salunke, "Seismic Behaviour of Multistorey Shear Wall Frame Versus Braced Concrete Frames," Archit. Res., vol. 4, no. 3, pp. 323-330, 2014.

2. A. Dharanya, S. Gayathri, and M. Deepika, "Comparison Study of Shear Wall and Bracings under Seismic Loading in Multi- Storey Residential Building,” vol. 10, no. 8, pp. 417-424, 2017.

3. P. Sanketh and B. D. V. C. M. Rao, "Seismic Strengthening Of Plan Irregular Rc Buildings With Re-Entrant Corners Using Shearwalls," pp. 21-26, 2016.

4. Divyashree M et al, "Comparison of Bracings and Shear Walls As Seismic Strengthening Methods To Buildings With Plan Irregularities," Int. J. Res. Eng. Technol., vol. 3, no. 6, pp. 205-210, 2014. 